\title{
Willingness to Pay for a COVID-19 Vaccine
}

\author{
Arcadio A. Cerda ${ }^{1}$ (]) Leidy Y. García ${ }^{1}$ (1) \\ Accepted: 6 February 2021 / Published online: 23 February 2021 \\ (c) The Author(s), under exclusive licence to Springer Nature Switzerland AG part of Springer Nature 2021
}

\begin{abstract}
Background The coronavirus disease (COVID-19) pandemic has considerably affected the lives of people worldwide, impacting their health and economic welfare, and changing the behavior of our society significantly. This situation may lead to a strong incentive for people to buy a vaccine. Therefore, a relevant study to assess individuals' choices and the value of change in welfare from a COVID-19 vaccine is essential.

Objective This study aimed to estimate the willingness-to-pay (WTP) value for a vaccine for COVID-19. We also identify the variables that influence individual vaccination decisions, which could be used in the design of vaccination promotion strategies.

Methods We use the contingent valuation method in its double-bounded dichotomous choice format. The estimation coefficients are calculated according to the maximum likelihood method under the assumption of a probit distribution. The sample consisted of 531 individuals, mainly from middle- and high-income socioeconomic groups from Chile between enrolled between 10 July and 10 August 2020.

Results The results show a high WTP for the COVID-19 vaccine, with a value up to US\$232. Income and education levels and having family members with COVID-19 increased the likelihood of persons paying for a vaccine. There is also a greater fear as the pandemic progresses that people will get sick from COVID-19.

Conclusions The high WTP value creates an opportunity for formulating public health policy. The results of this study suggest that governments can provide the vaccine free to low-income groups and allow those with higher incomes to acquire the vaccine through the private sector by paying. This will be useful especially for countries with economic difficulties.
\end{abstract}

\section{Key Points for Decision Makers}

In health systems with budget constraints, vaccination against COVID-19 could mix public and private financing, where people with the highest incomes pay for their vaccines.

Promotional campaigns to get vaccinated should focus primarily on people with less education and consider the motivating factors for this.

The possibility of getting vaccinated increases for people who have had relatives with COVID-19, so they can be considered part of the target group for vaccination campaigns.

Leidy Y. García

lgarcia@utalca.cl

Arcadio A. Cerda

acerda@utalca.cl

1 Faculty of Economics and Business, University of Talca, 1 Poniente 1141, Talca, Chile

\section{Introduction}

The coronavirus disease (COVID-19) pandemic has considerably affected the lives of people worldwide, affecting their health and economic welfare, significantly changing the behavior of our society, and affecting individuals' mental health [1-6]. Additionally, the reduction in global economic activity in most industries has reduced employment opportunities, among other impacts. This may cause people to increase their willingness to pay (WTP) for a vaccine to reduce possible adverse effects from the disease, despite some people refusing the vaccination because of ethical, religious, social, or economic reasons and fear [7-11].

We previously found that the WTP was about US\$184 in Chile between April and 5 May 2020 [6], which is almost five times higher than that found for Malaysia [11]. Among middle- and higher-income classes in Chile, at that time, the number of cases and deaths due to COVID19 were 9252 and 116, respectively (17 April 2020). However, since 7 July 2020, the cases and deaths have 
increased by $3,176 \%$ and $5566 \%$, respectively, in Chile (303,083 infected and 6573 deaths). In addition, the number of people in intensive care has increased from 387 to 2053 (a 430\% increase), and the availability of mechanical ventilators decreased by $37 \%$ (from 579 to only 364) [12]. Globally, cases and deaths increased by $435 \%$ and $260 \%$, respectively, for the same period [13]. Further, according to preliminary information from the Central Bank of Chile, the monthly Economic Activity Index in June fell by $12.4 \%$ compared to June of the previous year [14]. Moreover, the number of unemployed people increased by $42.9 \%$, and unemployment rose to $12.2 \%$ in the April-June 2020 quarter, which is the highest level of unemployment seen in Chile in this decade [15].

Given the increase in the number of infected people [16], as well as the reduction in economic activity and employment, it is expected that people's WTP for a vaccine against COVID-19 should increase after 3 months since the last study [6]. This is because people are experiencing a greater fallout from the pandemic. Despite the fact that some countries have already declared that the vaccine will be free of charge (Australia) [17], it is expected that in other countries it will be free only for the lowerincome groups, while the wealthier people will pay for their vaccines through private clinics, given the budget restrictions on health-care spending.

There are few studies on WTP for the upcoming vaccine against COVID 19; García and Cerda [6] for Chile, Harapan et al. [18] for Indonesia, Wong et al. [11] for Malaysia, and Sarasty et al. [19] for Ecuador. They all used the contingent valuation method (CVM); while the first used the double dichotomous format, the other two used the simple format, and found average values of WTP between US\$57.20 and US\$277. It should be noted that the doublebounded dichotomous choice format has the advantage of being statistically more efficient in estimating variance and obtaining precise confidence intervals for WTP $[20,21]$ than the simple format. Dong et al. [22] used the choice experiment method under the estimation of a logit model and found that the WTP for a vaccine with $90 \%$ effectiveness is between US\$68 to US $\$ 2986$ for China. Considering the existing literature, we also estimated the WTP using the CVM for the Chilean case, when the pandemic was at its peak in terms of infections, mortality, and the occupation of emergency beds, which could affect the risk perception of individuals and with it the valuation of the vaccine.

The objective of this study was to estimate the WTP for a COVID-19 vaccine in Chile and identify the main variables affecting this value. This will provide information about the social value of the vaccine and the tools necessary for designing public health policies on vaccination. We used CVM analysis in its double-bounded dichotomous choice format, using a probit distribution function (this method is frequently used in the valuation literature for goods and services) $[6,16,19,23-25]$. Additionally, this study aimed to obtain information on why some people refuse to pay for vaccination.

\section{Methods}

The objective of the contingent valuation of non-market goods is to find the value of the compensatory variation or equivalent variation associated with a change in the provision of the public good [26]. In other words, the contingent valuation determines whether the change in the provision of the vaccine implies a change in the level of well-being. This change in well-being is estimated through the WTP for the contingent or hypothetical benefactor, in our case the COVID-19 vaccine.

There are two methods for estimating the WTP using the theory of random utility: the method of choice experiments and the CVM. The first is used when there are more than two choice alternatives, while the second is used when there are only two alternatives (yes or no) [27, 28]. It is more appropriate to study the COVID-19 vaccine through the change in welfare, due to its provision, while considering the alternatives of paying or not paying for the vaccine. Therefore, given our objective and choice alternatives, we estimated the WTP through the CVM. This is the most widely used method in the literature and has the advantage of being direct, better reflecting the change in well-being, since information comes from the individuals themselves, and allows determination of the extant assessment [29-32]. Its main disadvantage lies in the hypothetical nature of the method, since individuals may not answer truthfully (e.g., the person believes that if they indicate that they would pay, then they would not qualify for a free vaccine if available) or a hypothetical bias generated by the differences between what the individual declares that he would pay and his actual behavior [32].

\subsection{Survey Description}

The information was collected through an online and selfadministered questionnaire (Supplementary Material 1). The survey was answered by 531 individuals between 10 July and 10 August 2020. The target population comprised people between 18 and 90 years of age, mainly in the middle- and higher-income groups, given that it is expected that lowerincome groups will get the vaccine for free from the government. The questionnaire was validated by experts through a focus group and a pilot survey using 53 individuals.

Active recruitment was used to reduce the limitations in data gathering. Open invitations were sent through social media networks and promoted using advertisements 
according to the objective of the research and the target group (similarity between social medial profile and characteristics required in the population). The initial number of questionnaires required based on a simple probability sampling, considering an error of 5\% and a maximum variance and confidence level of 95, was 386. The final sample size $(N=531)$ was greater, reducing the sampling error. Additionally, $87.4 \%$ of the population in Chile has access to the internet [33] and 71\% use social networks [34]. This reduces the representativeness problems of online surveys.

Research shows that an individual's WTP depends on several variables including individual preferences, income, taste, attitude, perception toward a vaccine (such as "good"), and sociodemographic characteristics $[35,36]$. Therefore, the questionnaire was divided into three sections to collect this information. The first section contained 20 questions related to pandemic knowledge, individuals' self-perception of their risk of infection, and information on their medical condition (chronic diseases, if any). The second section included two subsections, one related to the description of a contingent market as well as a question of WTP for a vaccine, and the other comprised individuals' reasons for their unwillingness to pay for a vaccine. Finally, the third section included two further subsections, one related to sociodemographic information (ten questions) and another related to educating children under the pandemic. However, this last section (16 questions) is not discussed in here.

Before the respondents were given access to the questionnaire, they were informed that the survey was voluntary and that the information that they provide will be confidential. Additionally, respondents were informed that their responses will be analyzed in aggregate form (not individually) and will not be disclosed as an individual response. Once they accepted these conditions and provided informed consent, access to the questionnaire was granted.

\subsection{Econometrics Analysis}

There are two approaches in the CVM: the Hanemann's indirect utility function [37] and Cameron's valuation function [38]. According to Park and Loomis [39], both approaches give similar values of the mean WTP and its interval. We use the Hanemann's approximation because it is simpler, more direct, and does not require specifying the form of the unobserved utility function. For the estimation of the WTP, we use the double dichotomous format since it has greater efficiency and less ambiguity about the recovered preferences [40]. Econometrically, we estimate the mean of the WTP based on a probit following Lopez-Feldman [41], under the double dichotomous format using Stata software release 16 (StataCorp, College Station, TX, USA). This allows efficient use of the individual information to estimate WTP while considering the covariates' effects [19, 25, 42].
The bid vector was obtained from a pre-survey of 114 individuals who expressed their WTP for a vaccine in an openended format. Using this information, we estimated the bid vector using an iterative routine with the objective of finding the minimum mean square error of the bid design. For this, we assumed a log-normal distribution with a limit of 10 bid values $\left(\operatorname{bid}_{i}\right)$. Using these bid values, we obtained the upper $\left(\operatorname{bid}_{\mathrm{u}}\right)$ and lower limits $\left(\mathrm{bid}_{\mathrm{l}}\right)$ of each by adding or subtracting half of its value, respectively (Table S1, Online Supplemental Material (OSM) 2).

The contingent market provided information on individuals with respect to the number of cases and deaths from COVID19 in Chile and the rest of world between 18 April and 8 July 2020. Moreover, information was provided about the number and changes in the number of people in intensive care and the availability of mechanical ventilators and the possible consequences of COVID-19, among other relevant information.

Subsequently, each respondent is assigned some random value of the payment vector. First, we offered a specific amount $\left(\mathrm{bid}_{i}\right)$; if the respondent was willing to pay that amount, we offered a higher amount $\left(\mathrm{bid}_{\mathrm{u}}\right)$; and if the respondent was not willing to pay the initial amount, we offered a lower amount $\left(\right.$ bid $\left._{1}\right)$. Figure 1 is a schematic representation of the doublebounded dichotomous choice experiment.

\section{Results}

\subsection{Summary Statistics}

The total valid responses reached 531 observations, wherein $17 \%$ (91 individuals) refused to pay for a vaccine (Fig. S1, OSM 2). The sample demographics included $71.3 \%$ medium- to high-income individuals, with an average monthly income of US $\$ 2440 ; 72.83 \%$ were adults between 30 and 59 years of age; $59.2 \%$ were women; $76.6 \%$ had a university education; and $43.4 \%$ had children attending school. Of these groups, $97.93 \%$ claimed that they were well informed about the implications of the COVID-19 pandemic; $54.6 \%$ stated having fears that had increased during the last 3 months of the pandemic; 78\% declared that they were risk averse; and $12.81 \%$ said they were risk neutral. Furthermore, $52 \%$ belonged to the private health system; $35.4 \%$ had chronic diseases; and $77.97 \%$ had relatives with chronic diseases (Table 1).

Most of the respondents displayed a high level of knowledge about the effect of SAR-CoV2 on health (65\%). The respondents agreed or strongly agreed $(75 \%)$ that the pandemic will reduce economic activity and employment. Considering the perception about government performance to combat the pandemic, less than $20 \%$ of the people believed that it has been good or excellent. Furthermore, when the actual perception was compared to the one recorded 3 
Fig. 1 Process of offering the different payment values (bid) to the respondents. bid $_{i}=$ initial payment vector, bid $_{1}=$ lowest bid respect to initial payment vector, and bid $_{\mathrm{u}}=$ highest bid respected to initial bid $_{i}$, for $i=1-10$ (quantity of offers). See the values of the bid and sampling distribution in Table S1, Online Supplemental Material 2

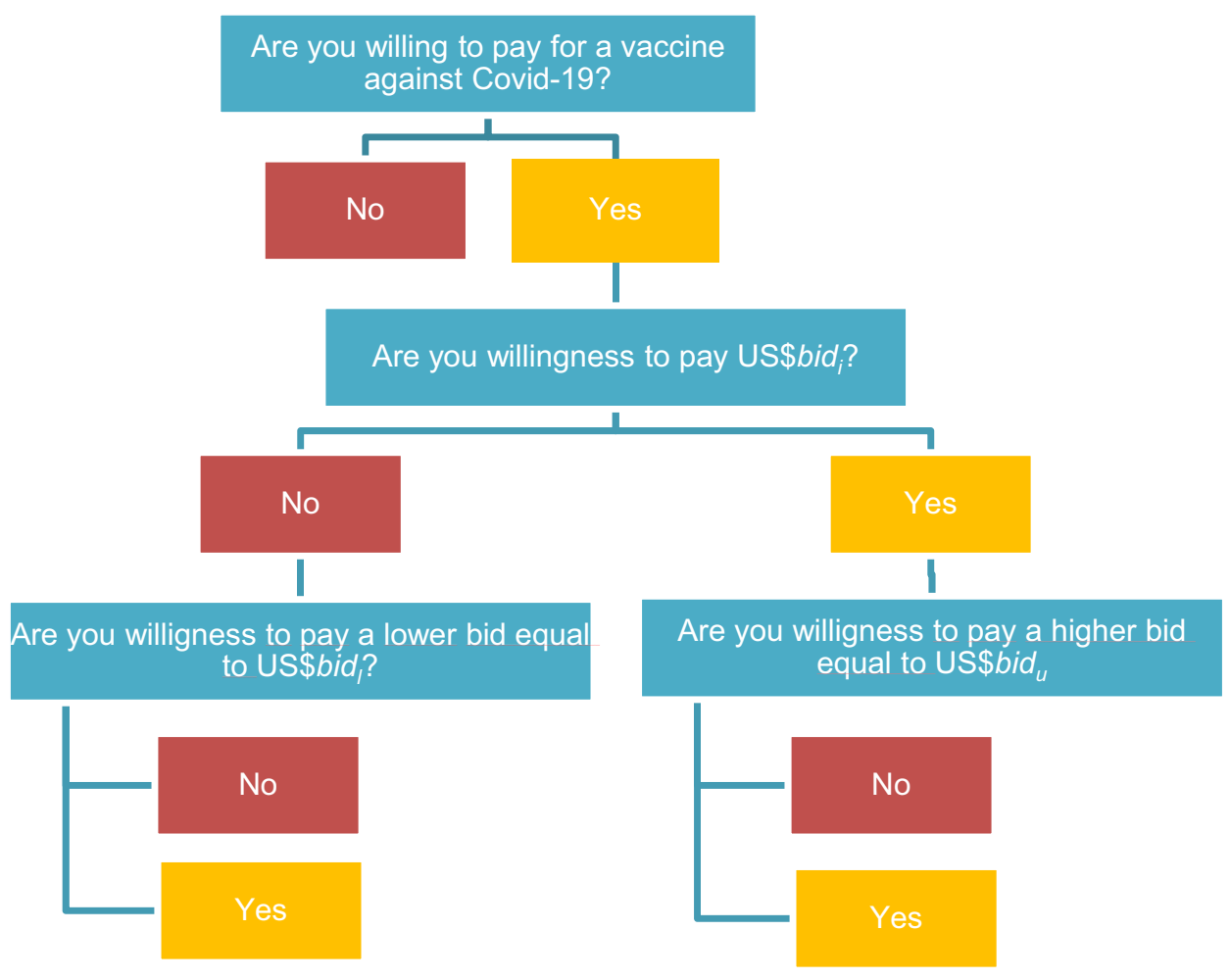

months ago, it was found that $51.79 \%$ believed that the government's performance in managing the pandemic had gotten worse (Table 2) (see OSM 1, section B, for more details of the scenarios).

\subsection{Model Estimation and Willingness-to-Pay Welfare Measures}

Following Lopez-Feldman [41], Table 3 shows the results from the double-bounded dichotomic choice models and the WTP. The basic model assumes that there are no other co-variables. It can be seen that the coefficient signs are in line with the literature, that is, an inverse relationship exists between the vaccine price and the probability of paying for the vaccine. This means that a higher price will reduce individuals' probability of paying for a vaccine. The expanded model represented the best-fit model, after considering 15 variables, where in addition to the vaccine price $(p<0.05)$, the co-variable income $(p<0.01)$, education level $(p<0.05)$, and the having relatives with COVID-19 $(p<0.05)$ all have a positive impact on the probability of paying for a vaccine against COVID-19.

Table 3 shows the main results of the welfare measures and the confidence intervals under different assumptions. These were estimated using the Krinsky and Robb approach with 10,000 repetitions [43]. The Wald test indicates that the model is statistically significant. Moreover, we present unrestricted welfare measures because this is corrected for individual cases where the WTP can become negative in the estimation process, and with this adjustment, the WTP increased by $10 \%$. For the expanded model, the unrestricted WTP estimate value is US $\$ 232$ per vaccine at $99 \%$ of confidence. This value is quite high, but it is reasonable for people from middle- and highincome groups. Additionally, to make our results more robust, the WTP was estimated through other methods (Table S2, OSM 2).

\subsection{Reasons for Refusing the Vaccine}

The main reasons for respondents refusing to pay for the vaccine are as follows: the government should pay for the vaccine (44\%), the vaccine is not important (16\%), I do not have enough money (11\%), those who caused the virus must pay for it $(10 \%)$, it is immoral to pay for a vaccine $(10 \%)$, and society has bigger problems/I do not want to pay (8\%). These results show that almost $90 \%$ of the refusal responses are protest responses (Fig. 2). It should be noted that the respondents can choose more than one option when rejecting WTP, reaching in our study a total of 116 choices from the 91 respondents.

\section{Discussion}

Our study showed a positive valuation of the WTP for a vaccine against COVID-19 and found it to be higher than the value found 3 months before this study [6] (56\% higher) 
Table 1 Demographic and social variables, number of respondents $(n)$, and percentage (\%)

\begin{tabular}{|c|c|c|c|c|c|}
\hline Variable & $\begin{array}{l}\text { Original } \\
\text { sample, } \\
N=531 \\
n(\%)\end{array}$ & $\begin{array}{l}\text { Estimation } \\
\text { sample, } \\
n=440 \\
n(\%)\end{array}$ & $\begin{array}{l}\text { Total rejec- } \\
\text { tion, } n=91 \\
n(\%)\end{array}$ & $\begin{array}{l}\text { Protest } \\
\text { reasons, } \\
n=78 \\
n(\%)\end{array}$ & $\begin{array}{l}\text { Income } \\
\text { reasons, } \\
n=13 \\
n(\%)\end{array}$ \\
\hline \multicolumn{6}{|l|}{ Age, years } \\
\hline $18-29$ & $61(12)$ & $57(13)$ & $4(4)$ & $3(4)$ & $1(8)$ \\
\hline $30-39$ & $120(22)$ & $105(24)$ & $15(16)$ & $13(17)$ & $2(15)$ \\
\hline $40-49$ & $136(26)$ & $113(26)$ & $23(25)$ & $19(24)$ & $4(31)$ \\
\hline $50-59$ & $130(25)$ & $99(23)$ & $31(34)$ & $27(35)$ & $4(31)$ \\
\hline$\geq 60$ & $83(15)$ & $65(14)$ & 17 (19) & 15 (19) & $2(15)$ \\
\hline \multicolumn{6}{|l|}{ Gender } \\
\hline Female & $212(40)$ & $182(41)$ & $30(33)$ & $28(36)$ & $2(15)$ \\
\hline Male & $314(59)$ & $255(58)$ & $59(65)$ & $48(62)$ & $11(85)$ \\
\hline Not defined & $4(1)$ & $3(1)$ & $2(2)$ & $2(3)$ & $0(0)$ \\
\hline \multicolumn{6}{|l|}{ Education } \\
\hline Preliminary school & $6(1)$ & $2(1)$ & $4(4)$ & $4(5)$ & $0(0)$ \\
\hline High school & $45(9)$ & $31(7)$ & $14(15)$ & $12(15)$ & $2(15)$ \\
\hline Technical & $73(13)$ & $52(12)$ & $21(23)$ & $19(24)$ & $2(15)$ \\
\hline University degree & $231(44)$ & 207 (47) & $24(26)$ & $19(24)$ & $5(38)$ \\
\hline Graduate degree & $175(33)$ & $148(34)$ & $27(30)$ & $23(29)$ & $4(31)$ \\
\hline \multicolumn{6}{|c|}{ Monthly income (US\$) } \\
\hline$<569$ & $90(17)$ & $56(13)$ & $34(37)$ & $28(36)$ & $6(46)$ \\
\hline $570-953$ & $62(12)$ & $45(10)$ & 17 (19) & $16(21)$ & $1(8)$ \\
\hline $954-1,476$ & $64(12)$ & $53(12)$ & $11(12)$ & $11(14)$ & $0(0)$ \\
\hline $1477-2186$ & $83(15)$ & $73(17)$ & $10(11)$ & $7(9)$ & $3(23)$ \\
\hline$>2186$ & $231(44)$ & $213(48)$ & $18(20)$ & $13(17)$ & $3(23)$ \\
\hline \multicolumn{6}{|l|}{ Type of health system } \\
\hline Public & $224(42)$ & $166(38)$ & $58(64)$ & $51(65)$ & $7(54)$ \\
\hline Private & $274(52)$ & $251(57)$ & $23(25)$ & $20(26)$ & $3(23)$ \\
\hline Other & $33(6)$ & $23(5)$ & $10(11)$ & $6(8)$ & $3(23)$ \\
\hline \multicolumn{6}{|c|}{ Fear of getting infected increased in last 3 months } \\
\hline & $290(55)$ & $247(56)$ & $43(47)$ & $36(46)$ & $7(54)$ \\
\hline \multicolumn{6}{|c|}{ Family or relative with COVID-19 } \\
\hline & $45(9)$ & $33(8)$ & $12(13)$ & $10(13)$ & $2(15)$ \\
\hline \multicolumn{6}{|c|}{ Family or relative recovered from COVID-19 } \\
\hline & $93(18)$ & $70(16)$ & $23(25)$ & $19(24)$ & $4(31)$ \\
\hline
\end{tabular}

Table 2 Context variables by frequency of respondents $(n)$ and percentage (\%)

\begin{tabular}{lllllll}
\hline Context variables & Mean & $\begin{array}{l}\text { Strongly } \\
\text { disagree, } n \\
(\%)\end{array}$ & Disagree, $n(\%)$ & $\begin{array}{l}\text { Neither agree or } \\
\text { disagree, } n(\%)\end{array}$ & Agree, $n(\%)$ & Strongly agree, $n(\%)$ \\
\hline Good knowledge about COVID-19 & 3.5 & $90(16.95)$ & $53(9.98)$ & $41(7.72)$ & $200(37.66)$ & $147(27.68)$ \\
Pandemic reduced employment & 3.7 & $85(16.01)$ & $47(8.85)$ & $2(0.38)$ & $205(38.61)$ & $192(36.16)$ \\
Pandemic reduced economic activity & 3.7 & $88(16.57)$ & $47(8.85)$ & $3(0.56)$ & $200(37.66)$ & $193(36.35)$ \\
Adapting work at home & 3.3 & $89(16.76)$ & $77(14.5)$ & $76(14.31)$ & $167(31.45)$ & $122(22.98)$ \\
Perception of good government response & 2.2 & $189(35.59)$ & $190(35.78)$ & $58(10.92)$ & $71(13.37)$ & $23(4.33)$ \\
Perception of improved government response & 2.1 & $110(20.72)$ & $165(31.07)$ & $61(11.49)$ & $85(16.01)$ & $110(20.72)$ \\
\hline
\end{tabular}


Table 3 Estimation of doublebounded discrete choice models and willingness-to-pay (WTP) estimates for the basic and expanded mode

\begin{tabular}{lll}
\hline Variable & $\begin{array}{l}\text { Basic model } \\
\text { Coefficient (standard error) }\end{array}$ & $\begin{array}{l}\text { Expanded model } \\
\text { Coefficient (standard error) }\end{array}$ \\
\hline Mean WTP (beta) (\$) & $252.213^{\mathrm{a}}$ & $231.924^{\mathrm{a}}$ \\
& $(16.668)$ & $(16.497)$ \\
Constant & & 6.465 \\
& & $(13.102)$ \\
Income & & $53.488^{\mathrm{a}}$ \\
& & $(21.268)$ \\
Education & & $29.412^{\mathrm{c}}$ \\
& & $(21.267)$ \\
Relative with COVID-19 & $103.376^{\mathrm{b}}$ \\
Sigma & $296.07^{\mathrm{a}}$ & $(60.638)$ \\
Sample & $(20.675)$ & $278.83^{\mathrm{a}}$ \\
log-likelihood & 440 & $(19.426)$ \\
Wald Chi2(3) & -581.541 & 440 \\
WTP estimates & & -559.285 \\
$95 \%$ confidence interval WTP $(\$)$ & $35.42^{\mathrm{a}}$ \\
\hline
\end{tabular}

Values are in US dollars

${ }^{\mathrm{a}} p \leq 0.01$

${ }^{\mathrm{b}} p \leq 0.05$

${ }^{\mathrm{c}} p \leq 0.10$

in the case of Chile. Because the sample population in this study is different, it does not necessarily mean that the value has increased since the beginning of the pandemic, but it can indicate that the population now values the vaccine more. The WTP is about 7.5 times higher than that found in the Malaysian study (US\$30.70) [25], but within the range of the WTP found in the Romanian study, which was US\$59.26-US\$474.08 for the high-income population, and US\$23.70-US\$237.04 for the general population [44]. This can be explained by the fact that the per capita income of Chile is $31.5 \%$ greater than that of Malaysia and $15.3 \%$ higher than that of Romania [45]. Moreover, the results are consistent with three issues: first, people became more afraid of becoming infected as the pandemic progressed; second, people's perception of the government's performance in addressing the pandemic has worsened; and finally, having relatives with COVID-19 had an impact on people. The above explanation represents the evolution of the WTP in Chile. Moreover, people with a higher income were more likely to pay for a vaccine, showing that in terms of public policy, the vaccine may be free for low-income groups while higher-income groups could pay for it.

Further, our study found that the acceptance rate of vaccination for COVID-19 was $83 \%$, which is within the range of that in other studies and surveys, varying between $44 \%$ in Romania to $87 \%$ in Australia [46]. Therefore, public health policymakers should consider these findings on vaccination rates and WTP to guide the strategies for vaccination campaigns against COVID-19. For example, if a country faces a significant budget constraint, it could provide the vaccine for free to at-risk and economically vulnerable groups only and have the higher-income population pay for the vaccine. Bearing in mind that the WTP could be influenced by individual perception of the effectiveness of the vaccine, the baseline scenario presented to respondents and different socioeconomic variables, the findings are in line with those of Harapan et al. [18].

Additionally, our findings show that education is a determining variable in evaluating the vaccine. Therefore, information campaigns should focus on education and motivation toward vaccination for COVID-19. Specifically, according to our results, vaccination campaigns should focus on promoting the vaccine to groups with a low educational level, since they are less likely to want to be vaccinated. This is because their health literacy and education may be lower [47] and they are unaware of the risks of the disease [48]. Additionally, people who have experienced the disease at home are more likely to pay and get vaccinated. Another important aspect is to consider the reasons for refusing to pay for the vaccine, since results show that there are small groups of the population that do not consider the vaccine to be important and will not get vaccinated; this is a risk to public health [49] . Therefore, any campaign that is developed should consider this group as well. 
Fig. 2 Sample distribution of willingness to pay (WTP) and frequency of refusal reason. $\operatorname{bid}_{i}=$ initial payment vector, bid $_{1}=$ lowest bid respect to initial payment vector, and $\operatorname{bid}_{\mathrm{u}}=$ highest bid respected to initial $\mathrm{bid}_{i}$, for $i=1$ to 10 (quantity of offers). See the values of the bid and sampling distribution in Fig. S1, Online Supplemental Material 2. *Respondents could choose more than one option when rejecting WTP, reaching in our study a total of 116 choices from the 91 respondents

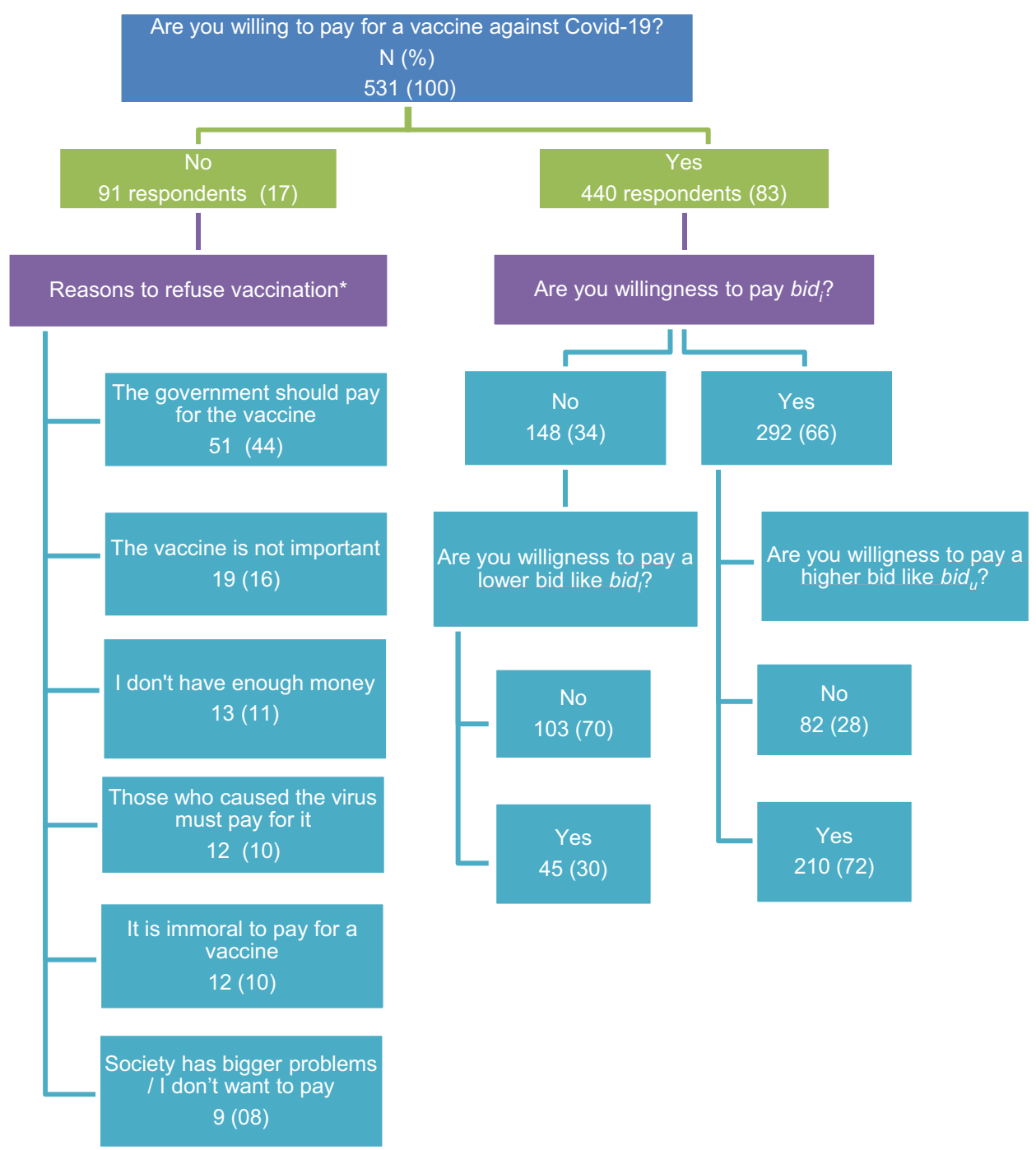

If we compare the information regarding the situation of the COVID-19 pandemic given to the respondents, corresponding to 7 July 2020 , with respect to what is currently happening, specifically on 20 January 2021, we can observe that the diagnosed cases have increased by $125 \%$, reaching a total of 680,740 people, where the recovered cases are 639,091 ; the number of deaths increased by $168 \%$, reaching a total of 17,594 in the country. However, there has been a $50 \%$ reduction in the number of people hospitalized in intensive care, reaching a total of 1024 individuals. Given the changes in the situation of the pandemic, it can probably affect the WTP, as we observed in our two studies with respect to Chile. The direction of the change in the WTP in the future will vary depending on how individuals weigh the different factors of the socioeconomic and health environment, including the implicit risks of being infected or the possibility of obtaining a vaccine as soon as possible.

There are some limitations to this study, the first being the data collection method since the sample may not be fully representative of the middle- and higher-income level population of Chile, despite the fact that an active recruitment system was used to reduce this limitation. Additionally, although CVM is widely used, some authors postulate that biases can be generated by the respondent's lack of understanding of the contingent market [50]. In addition, the online data collection method is a limitation of this study, but given the travelling restrictions present in countries, it was the best way available to obtain relevant data. Thus, the sample may not be fully representative of the population of Chile. However, we used an active recruitment system to reduce this limitation of our research. 


\section{Conclusions}

The progression of the pandemic has affected not only the people's health of people but also their livelihoods. However, it may have also influenced the WTP for a vaccine against COVID-19. Specifically, fear of infection may be increasing as well as the probability of the WTP a higher price for vaccines. In addition to education level and income, this value and probability is also positively affected by an individual having had a relative or family member sick with COVID-19. However, the same result does not hold when people have recovered. Based on the findings in this study, the government could provide the vaccine for free to lowincome groups and allow high income groups to purchase the vaccine in the private sector. Additionally, any vaccination campaign design should focus on influencing education through information and increasing the vaccine's acceptance rate, while considering the country's public health situation. Therefore, every country should design its own campaign according to its public health situation, considering the general guidelines of international scientific studies.

Supplementary Information The online version contains supplementary material available at https://doi.org/10.1007/s40258-021-00644-6.

Acknowledgements Not applicable.

\section{Declarations}

Funding Not applicable.

Conflicts of interest/competing interests The authors declare that there no conflicts of interest that are relevant to the contents of this article.

Ethics approval The project associated to this article was presented to the Ethics Committee of the institution. This research has exemption status: anonymous and non-sensitive survey research.

Consent to participate Informed consent was obtained from all the respondents included in the study.

Consent for publication Not applicable.

Availability of data and materials The datasets that support the findings of this study are available from the corresponding author upon reasonable request.

Code availability Not applicable.

Authors' contributions AC contributed to the conceptualization of the study, methodology, formal analysis, resources, writing, and original draft preparation. LG contributed to formal analysis, investigation, writing, reviewing, and editing the final article. All authors read and approved the final manuscript.

\section{References}

1. Torales J, O'Higgins M, Castaldelli-Maia JM, Ventriglio A. The outbreak of COVID-19: coronavirus and its impact on global mental health. Int J Soc Psychiatry. 2020;66(4):317-20. https://doi. org/10.1177/0020764020915212.

2. Ahmad T, Haroon H, Baig M, Hui J. Coronavirus disease 2019 (COVID-19) pandemic and economic impact. Pak J Med Sci. 2020;36(COVID19-S4):S73-8. https://doi.org/10.12669/pjms.36. COVID19-S4.2638.

3. Acter T, Uddin N, Das J, Akhter A, Choudhury TR, Kim S. Evolution of severe acute respiratory syndrome coronavirus 2 (SARSCoV-2) as coronavirus disease 2019 (COVID-19) pandemic: a global health emergency. Sci Total Environ. 2020;730:138996. https://doi.org/10.1016/j.scitotenv.2020.138996.

4. Koon OE. The impact of sociocultural influences on the COVID19 measures: reflections from Singapore. J Pain Symptom Manag. 2020;60(2):e90-2. https://doi.org/10.1016/j.jpainsymma n.2020.04.022.

5. Mudatsir M, Anwar S, Fajar JK, Yufika A, Ferdian MN, Salwiyadi S, et al. Willingness-to-pay for a hypothetical Ebola vaccine in Indonesia: a cross-sectional study in Aceh. F1000Res. 2019;8(1441):1441. https://doi.org/10.12688/f1000resea rch.20144.1.

6. García LY, Cerda AA. Contingent assessment of the COVID-19 vaccine. Vaccine. 2020;38(34):5424-9. https://doi.org/10.1016/j. vaccine.2020.06.068.

7. Yaqub O, Castle-Clarke S, Sevdalis N, Chataway J. Attitudes to vaccination: a critical review. Soc Sci Med. 2014;112:1-11. https ://doi.org/10.1016/j.socscimed.2014.04.018.

8. Mello MM, Silverman RD, Omer SB. Ensuring uptake of vaccines against SARS-CoV-2. N Engl J Med. 2020. https://doi. org/10.1056/NEJMp2020926.

9. Le Thanh T, Andreadakis Z, Kumar A, Roman RG, Tollefsen S, Saville M, et al. The COVID-19 vaccine development landscape. Nat Rev Drug Discov. 2020. https://doi.org/10.1038/d41573-02000073-5.

10. Rajamoorthy Y, Radam A, Taib NM, Rahim KA, Munusamy S, Wagner AL, et al. Willingness to pay for hepatitis B vaccination in Selangor, Malaysia: a cross-sectional household survey. PLoS ONE. 2019;14(4):e0215125. https://doi.org/10.1371/journ al.pone.0215125.

11. Wong LP, Alias H, Wong P-F, Lee HY, AbuBakar S. The use of the health belief model to assess predictors of intent to receive the COVID-19 vaccine and willingness to pay. Hum Vaccines Immunother. 2020;16(9):2204-14. https://doi.org/10.1080/21645 515.2020 .1790279 .

12. Gobierno de Chile: Cifras Oficiales COVID-19. (2021). http:// www.gob.cl/coronavirus/cifrasoficiales/ttp://epi.minsal.cl/infor mes-covid-19/. Accessed 20 Jan 2020.

13. Ministerio de Ciencia y Tecnología: Bases de datos COVID-19, Gobierno de Chile. (2020). https://www.minciencia.gob.cl/covid 19. Accessed 7 Aug 2020.

14. Central Bank of Chile: Monthly economic activity index (Imacec) June. (2020). Accessed 20 Sept 2020.

15. National Institute of Statistics: Boletín Estadístico: Empleo trimestral June. (2020). Accessed 20 Sept 2020.

16. Al-Hanawi M, Almazrou S, Alsharif M, Yunusa I. PNS63 willingness to pay for health insurance using the contingent valuation method: a systematic review. Value Health. 2019;22:S773. https ://doi.org/10.1016/j.jval.2019.09.1965. 
17. Ministers Department of Health: Australia secures a further 50 million doses of COVID-19 vaccine. (2020). http://www.healt h.gov.au/ministers/the-hon-greg-hunt-mp/media/australia-secur es-a-further-50-million-doses-of-covid-19-vaccine. Accessed 5 Nov 2020.

18. Harapan H, Wagner AL, Yufika A, Winardi W, Anwar S, Gan AK, et al. Acceptance of a COVID-19 vaccine in Southeast Asia: a cross-sectional study in Indonesia. Front Public Health. 2020. https://doi.org/10.3389/fpubh.2020.00381.

19. Sarasty O, Carpio CE, Hudson D, Guerrero-Ochoa PA, Borja I. The demand for a COVID-19 vaccine in Ecuador. Vaccine. 2020;38(51):8090-8. https://doi.org/10.1016/j.vacci ne.2020.11.013.

20. Hanemann M, Loomis J, Kanninen B. Statistical efficiency of double-bounded dichotomous choice contingent valuation. Am J Agric Econ. 1991;73(4):1255-63. https://doi.org/10.2307/12424 53.

21. Kanninen BJ. Optimal experimental design for doublebounded dichotomous choice contingent valuation. Land Econ. 1993;69(2):138-46. https://doi.org/10.2307/3146514.

22. Dong D, Xu RH, Wong EL-Y, Hung C-T, Feng D, Feng Z, et al. Public preference for COVID-19 vaccines in China: a discrete choice experiment. Health Expect. 2020. https://doi.org/10.1111/ hex.13140.

23. Kabir KMA, Hagishima A, Tanimoto J. Hypothetical assessment of efficiency, willingness-to-accept and willingness-to-pay for dengue vaccine and treatment: a contingent valuation survey in Bangladesh. Hum Vaccines Immunother. 2020. https://doi. org/10.1080/21645515.2020.1796424.

24. Wolff E, Larsson S, Svensson M. Willingness to pay for health improvements using stated preferences: prevention versus treatment. Value Health. 2020;23(10):1384-90. https://doi. org/10.1016/j.jval.2020.06.008.

25. Wong LP, Alias H, Wong P-F, Lee HY, AbuBakar S. The use of the health belief model to assess predictors of intent to receive the COVID-19 vaccine and willingness to pay. Hum Vaccines Immunother. 2020. https://doi.org/10.1080/21645515.2020.17902 79.

26. Johnston RJ, Boyle KJ, Adamowicz W, Bennett J, Brouwer R, Cameron TA, et al. Contemporary guidance for stated preference studies. J Assoc Environ Resour Econ. 2017;4(2):319-405. https ://doi.org/10.1086/691697.

27. Brandt SJ, Lavin FV, Hanemann WM. Designing contingent valuation scenarios for environmental health: The case of childhood asthma. In: University of California B, Department of Agricultural and Resource Economics editor. CUDARE working papers 1076. http://www.purl.umn.edu/470772008. Accessed 12 Aug 2020.

28. Freeman A III, Herriges J, Kling C. The measurement of environmental and resource values. New York: Routledge; 2014.

29. Klose T. The contingent valuation method in health care. Health Policy. 1999;47(2):97-123. https://doi.org/10.1016/S0168 -8510(99)00010-X.

30. Settumba SN, Shanahan M, Botha W, Ramli MZ, Chambers GM. Reliability and validity of the contingent valuation method for estimating willingness to pay: a case of In vitro fertilisation. Appl Health Econ Health Policy. 2019;17(1):103-10. https:// doi.org/10.1007/s40258-018-0433-3.

31. Cuccia T. Contingent valuation. Handbook of cultural economics. 3rd ed. Cheltenham: Edward Elgar Publishing; 2020.

32. Bayoumi AM. The measurement of contingent valuation for health economics. Pharmacoeconomics. 2004;22(11):691-700. https://doi.org/10.2165/00019053-200422110-00001.
33. OCDE: OECD economic surveys: Chile. https://doi. org/10.1787/eco_surveys-chl-2018-en (2018). Accessed 30 Sept 2020.

34. Subsecretaría de Telecomunicaciones de Chile: Undersecretariat of Telecommunications of Chile, Gobierno de Chile. (2020). https ://www.subtel.gob.cl/estudios-y-estadisticas/internet/. Accessed 30 Sept 2020.

35. Boyle KJ. Contingent valuation in practice. In: Champ P, Boyle $\mathrm{K}$, Brown T, editors. A primer on nonmarket valuation. The economics of non-market goods and resources. Dordrecht: Springer; 2017. p. 83-131.

36. Cerda A, Garcia L, Albornoz D. Parents willingness to pay for a human papillomavirus vaccine to protect their adolescent daughters Maule Region, Chile. Salud Publica Mex. 2014;56(1):48-55.

37. Hanemann M. Welfare evaluations in contingent valuation experiments with discrete responses. Am J Agric Econ. 1984;66(3):222-41.

38. Cameron TA. A new paradigm for valuing non-market goods using referendum data: maximum likelihood estimation by censored logistic regression. J Environ Econ Manag. 1988;15(3):35579. https://doi.org/10.1016/0095-0696(88)90008-3.

39. Park T, Loomis J. Comparing models for contingent valuation surveys: statistical efficiency and the precision of benefit estimates. Northeast J Agric Resour Econ. 1992;21(2):170-6. https://doi. org/10.1017/S0899367X00002695.

40. Haab TC, McConnell KE. Valuing environmental and natural resources: the econometrics of non-market valuation. Cheltenham: Edward Elgar Publishing; 2002.

41. Lopez-Feldman A. Introduction to contingent valuation using Stata. (2012). https://www.econpapers.repec.org/paper/pramp rapa/41018.htm. Accessed 6 Sept 2020.

42. Harapan H, Wagner AL, Yufika A, Winardi W, Anwar S, Gan AK, et al. Acceptance of a COVID-19 vaccine in Southeast Asia: a cross-sectional study in Indonesia. Front Public Health. 2020;8:381. https://doi.org/10.3389/fpubh.2020.00381.

43. Park T, Loomis J, Creel M. Confidence intervals for evaluating benefits estimates from dichotomous choice contingent valuation studies. Land Econ. 1991;67(1):64-73.

44. Berghea F, Berghea CE, Abobului M, Vla VM, et al. Willingness to pay for a for a potential vaccine against SARS-CoV-2/ COVID-19 among adult persons. Preprinr (Version 1) available at Research Square. 2020. https://doi.org/10.21203/rs.3.rs-32595 $/ \mathrm{v} 1+$.

45. The World Bank: GDP per capita (current US\$). (2020). https:// www.data.worldbank.org/indicator/NY.GDP.PCAP.CD. Accessed 29 Aug 2020.

46. Feleszko W, Lewulis P, Czarnecki A, Waszkiewicz P. Flattening the curve of COVID-19 vaccine rejection: a global overview. SSRN Electron J. 2020. https://doi.org/10.2139/ssrn.3631972.

47. Paakkari L, Okan O. COVID-19: health literacy is an underestimated problem. Lancet Public Health. 2020;5(5):e249-50. https ://doi.org/10.1016/S2468-2667(20)30086-4.

48. May T. Public communication, risk perception, and the viability of preventive vaccination against communicable diseases. Bioethics. 2005;19(4):407-21. https://doi.org/10.111 1/j.1467-8519.2005.00452.x.

49. Hussain A, Ali S, Ahmed M, Hussain S. The anti-vaccination movement: a regression in modern medicine. Cureus. 2018;10(7):e2919. https://doi.org/10.7759/cureus.2919.

50. Hausman J. Contingent valuation: from dubious to hopeless. J Econ Perspect. 2012;26(4):43-56. https://doi.org/10.1257/ jep.26.4.43. 